\title{
PRESCRIPCION DE CREDITOS CONTRA LOS AYUNTAMIENTOS
}

Es sumamen:e interesante el problema de la prescripción de los créditos contra los Ayuntamientos, con vista de la varia jurisprudencia del Tribunal Supremo, sobre el hecho de la interrupción de la prescripción y el reconocimiento de ia ideuda por la entidad municipal, derivados de presunciones de voluntad, al incluir en la cuenta de "Resultas", en climplimiento de preceptos legales, ob.igaciones reconocidas en anterior presupuesto.

Las sentencias de aquel Tribunal, de 24 de febrero de 1896,18 de marzo de 1902 y 10 de noviembre de 1920 afirman que la inclusión en presupuestos de obligaciones reconocidas, en cumplimiento de preceptos legales, no supone un reconocimienio de la deuda, que interrumpa la prescripción ganada, siendo necesario para ello la existencia de o:ros actos que revelen la deliberanda voluntad de la Corporación de dejar vivo e: crédito, entendiendo que aquellos hechos no pasan de ser meras operaciones de contadiria, sin trascendencia en la relación juridica entre acreedor y deudor.

Otro grupo de sentencias rectificó el anterior criterio, siendo la más importantes la de 4 de diembre de 1918, que sienta la doctrina de que a inclusión de un crédito en presupuestos. implica la interrupcón de la prescripción y la de 27 de septiembre de 1927, que declara: "La prescripción de las acciones se inierrumpe por cualquier acto de reconocimiento de la deuda por el deudor, y el hecho de que haya figurado en el presupuesto del Ayrntamiento la existencia de la dewda deste 1905 en un documento que es público como lo es el presupuesto mun cipal, implica el reconocimiento de la deuda; y no habiendo pasado e! lapso de cinco años, desde que por última vez se iricluyó en presupuesio la cantidad que se reclamaba por los recurrentes hasta la fecha de esa reclamación, es lógica consecuencia que no ha prescripto la acción para reclamar el pago de esa deuda, de acuerdo con lo estab ecifo en la sentencia de: Tribural St:premo de 4 de diciembre de 1918" ("Gac." 17 octubre 1928).

Por último, la sentencia de 10 de diciembre de 1930 agrega que la inclusión de una deuda en la cuenta de Resultas del presupuesto municipal equivale a su reconocimiento, interrumpierdo la prescripción.

Dada la doctrina contradictoria contenida en las sentencias del Tribunal Supremo, considenamos de interés sacar a la luz pública los diversos aspectos de a cuestión, $y$, sin pretensiones de ninguna clase, aspiramos en este artícilo llamar la atención de los Ayuntamientos, para que medien sobre el alcance, significación y consecuencias de los ac:os administrativos, que puedan suponer 12 renuncia de la prescripción gunada y el reconocimiento tácito de las deudas.

En primer lugar, conviene destacar el contenido del artículo ro2 del Reglamento 
de Hacienda municipal de 23 de 2 gosto de 1924 que, bajo el epigrafe de "Créditos contra los Ayun amientos", declara que prescribirá el derecho al cobro de los reconocidos por ia realización de obras y prestación de servicios, al transcurso de los cinco años desde que fuera notificada la liquititación.

Este precepto, de una sencillez incuestionable, marca el plazo de extinción de los créditos por el fenómeno de la prescripción, de.erminando concretamente el momento desde el cual debe hacerse el cómputo. A pesar de su expresión cara y rotunia se ha desviado su sentido, al relacionarlo con otros artículos del Estatuto municipal, Ley de Administrac ón y Contabilidad de la Hacienda pública y Código Civi, cuyos textos han sido in.erpretados de distinta marera a través de la inconstante jurisprudencia.;

El artículo 15 del Reglamento de Hacienda municipal declara vigente la Ley de Administración y Contabilidad, en cuanto no se oponga a las normas contenidas en el Esiatuto municipal y el propio Regamento. El artículo 25 de dicha Ley confirma la doctrina sentada en 102 del Reglamento de Hacienda minicipal, por lo que no

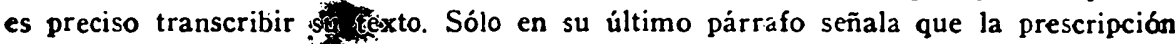
se interrumpirá por cuáguluera de los medios fijatos en el Código Civil, por lo que hemos de recurrir a éste para conocer qué actos tienen tal virtualidad. En efecto, el artículo 1973, entre los procedimientos de interrupción de la prescripción comprende. el de reconocimiento de la deuda por el deufor, que únicamente nos conviene destacar para el desarrollo de este trabajo.

Con tales antecedentes, situamos el problema de la interrupción de los créditos contra los Ayuntam en:os, partiendo de su reconocimierto presunto. Este se produce, según el texto del artículo 1.935 del Código Civil, mediante la renuncia tácita de la prescripción, 'cuando aquella resulte de actos que hacen suponer el abardono del derecho adquirido.

Reconocida una deuda e incluida en el presupuesto municipal, basta e: transcurso de cinco años para su extinción, si en este plazo no ha producido el acreedor reclamación judicial o extrajudicial o no ha efec:uado la entidad municipal un acto de reconocimiento de la deuda, doctrina que se deduce de la interpretación congruente de los artículos 25 te la Ley de Administración y Contabilidad, roz del Reglamento de Hacienda municipal y 1.973 del Código Civil.

¿Pero cuándo es legítimo apreciar la existencia de actos de la Corporación municipal que suponga el abanjono del derecho adquirido y renunciada tác tamente la prescripción a que se refiere e último párrafo del artículo 1.935 del Código civil?

Para el Tribunal Supremo, según se deduce de las sentencias últimamente citadas, bas.a incluir la deuda en la relación de acreedores de: Ayuntamiento, parte integrante de la cuenta de "Resultas", en cumpl miento del mandato contenido en el primer párrafo del artícu o I4 del Reglamento de Hacienda municipal, en desarrollo del 304 del Es:atuto municipal, que dice textualmente: "Las obligaciones reconocidas y no satisfechas y los derechos liquidados y no realizatos e: último día del ejercicio, se comprenderán como resultas en el capítulo y cuenta que se abra al presupuesto del nuevo ejercicio, priv a liquidación que se practicará dentro de los veinte días siguientes al término de cada ejercicio por el lnterventor y que se someterá a la aprcbación de la Comisión permanente."

Parece ser, según la doctrina recierte de la jurisprudencia, que el fenómeno de la prescripción de lus créd tos contra los Ayuntamientos comienza desde la expulsión de la deuda de la relación de acreedores del Municipio, consumándose al transcurso 
de cinco años; y que cada inclusión de la deuda en las resultas del presupuesto liquidafo, "es suficiente por sí solo para interrumpir la prescripción"... "con lo que cada año renovaba el reconocimiento de ba obligación", deducción ob:en:da de la doctrina, afirmada por la. Sala de lo Civil en sentencia de 26 de junio de 1928.

Como puete observarse, la an:er:or consecuencia es peligrosa y sumamente perjudicial para, los Ayuntamientos, pues, según ella, se verán privados de obtener los beneficios derivados de la prescripción de las acciones.

Su contenido no interpreta debidamente los artículos 304 del Estatuto municipal y 14 del Regamento de Hacienda municipal, que obligan a los Ayuntamientos a consignar en la cuen:a de "Resultas" las obligaciones reconocidas y no satisfechas en cada prest:puesto. Ello es evidente, puesto que, si por precepto legal se exige incluir aquellars obligaciones en las resultas del presupuesto, su incumplimiento infringiría los artículos ci:ados, no pudiendo efectuarse su eliminación de la relación de acreedores del Muricipio hasta la prescripción del crédito; y si cada inclusión lleva aparejado el reconocimiento de la deuda, con eficacia para interrumpir la prescripción ganada, ce daría el absundo de que tales obligaciones serian imprescriptibles, criterio que pugna francamen:e con los artículos 25 de la Ley de Administración y Contabilidad y 102 del Reglamento de Hacienda municipal.

Armonizando el cortenido de tales artículos, podría llegarse a la conclisión lógica de que el cumplimiento de un precepto 'egal no puede tener una significación juridica que él no expresa, sin que sea permitido deducir de su cumplimiento, en la mayor parte de los casos de carácter formulario, una renuncia tácita de la prescripc:ón gana.ja. Sería preciso, para su validez, que dicha renuncia, como acto de enajenación, se manifestare de una manera cxpresa y terminante, en la forma que normaimente se exige a las declaraciones de voluntad de las Corporaciones municipales.

Hemos dicho que la renuncia de la prescripción supone un acto de enajenación. Esta afirmación se deduce del tex:o del inciso primero del artículo r.935 del Código civil, que copiamos seguidamente: "Las persoras con capacidad para enajenar pueden renunciar la prescripción ganada." Esta deciaración suscita otro problema, si bien. no se refiera sino a los Municipios de más de 20.000 habitantes.

El artículo i4 Jel Reglamento de Hacienda municipal atribuye a la competencia de la Comisión permanente la aprobación de la cuenta de "Resulias" que ha de incorporarse al presupuesto del ejercicio en que se produce.

Ya sabemos que en esa cue zta se han de incluir las obligaciones municipales reconocidas y no satisfechas. Y dado el significajo que el Tribtral Supremo adjudica a tal inclusión, y, a pesar de ella, ¿puede vál:damente la Comisión permanente, de manera expresa o tácita, erajenar los derechos del Municipio? Según aquel Tribunal de la aprobación de la relación de acreedores del Municipio se deduce tácitamente el reconocimien:o de la deuda y la renuncia de la prescripción ganada, que son propiamente modalidades de enajenación de un derecho.

Mas esta interpretación se halla en abierta contradicción con el texio del párrafo primero en la relación con el apartado tercero del artículo 105 de la Ley municipal, que confiere con carácter especial a la competencia del Ayuntamiento Pleno la enajenación de derechos. Careciendo la Comisión permanente de capacidad para enajenar derechos del Municipio y siendo ella el requisito esencial para renunciar la prescripción ganada, según exige el artículo 1.935 del Código civil, no puede atribuírsele a los actos que realice una deducción presunta de roluntad para concluir un negocio 82 jurídico que expresamente no puede llevar a cabo. 
En cuanto a ios Municipios de menor vecindario que acttan a travts del Ayanta miento pleno ¿cómo ha de resolverse el conflicto?

Dada la significación actual de la docirina jurisprudencial, cada aprabación anual de la reación de acreedores del Municipio, que debe efectuarse en cumplimiento del artículo 304 del Estatuto municipal, supone un ac:o interruptorio de la prescripción y de reconocimiento de la deula, que inyecta al crédito nueva vida, sin que se vea la posibilidad de encontrar el momento del comienzo de la prescripciba extin:iva del crédito.

En este supuesto, la institución de la prescripción de los créditos contra los Ayuntamientos por el trarscurso de los plazos marcajos en los artículos 102 del Reglamento de Hacienda municipal y 25 de la Ley de Administración y Contabilidad, es letra muerta dada la s:gr.ificación que se le ha dado por la jurisprudencia al mandato contenifo en el artículo 14 de aquel Reglamento, que desarrolla el 304 vel Estatuto.

Se hace preciso, para que la prescripción extintiva de las acciones cumpla sa finalidad con respecto a los Municipios, volver a la doctrina tradicional contenida en las sentencias de 24 de febrero de 1896,18 de marzo de 1902 y 10 de noviembre de 1920.

De este moło se vivificará una inst:tución que prácticamente ha sido abolida del ámbito municipal, por la imposibilidad de su aplicación, adjudicándole el sentido Ide sanción a la inactividad del titular del crédito, declaranfo ext'nguido éste al no ejercitar las acciones oporturas en el transcurso del tiempo señalado por la Ley, idea generadora de la prescripción extintiva.

\section{Jose Serrano Ventura,} Sccretario del Excmo. Ayuntamiento de Lérida 